\title{
PARAÍSOS PERDIDOS OU PRESERVADOS: OS MÚLTIPLOS SENTIDOS DA CIDADANIA EM ÁREAS DE PROTEÇÃO AMBIENTAL
}

\author{
Virgínia Villas Boas Sá Rego ${ }^{\text {i }}$
}

"Todos têm direito ao meio ambiente ecologicamente equilibrado, bem de uso comum do povo e essencial à sadia qualidade de vida, impondo-se ao Poder Público e à coletividade o dever de defendê-lo e preservá-lo para as presentes e futuras gerações"

(Constituição da República Federativa do Brasil; Artigo 225\%).

"As noções de importância, de necessidade, de interesse são mil vezes mais determinantes que a noção de verdade. Não, de forma alguma, porque elas a substituam, mas porque medem a verdade do que digo" (Deleuze).

\section{INTRODUÇÃO}

Este trabalho busca refletir sobre a complexidade do termo cidadania, que pode assumir múltiplos sentidos e ser utilizado em diversos contextos: como conceito teórico das Ciências Sociais, como categoria orientadora do discurso jurídico-administrativo ou enunciada pelos atores sociais no decorrer das lutas políticas em defesa de seus interesses e necessidades.

Insere-se na pesquisa desenvolvida no Doutorado em Meio Ambiente (PPGMA) da Universidade do Estado do Rio de Janeiro (UERJ) ${ }^{\text {ii }}$ sobre os processos participativos na gestão de duas áreas de proteção ambiental (APA), Unidades de Conservação da Natureza de uso sustentável, situadas na Bacia Hidrográfica do Rio Macaé (RJ), que podem ser reconhecidas por apresentarem certa identidade geográfica, histórica e cultural: APA Estadual de Macaé de Cima ${ }^{\text {iii }}$ e APA Municipal do Sana ${ }^{\text {iv }}$. Procurando identificar as múltiplas forças que influem no processo de construção social do ambiente, nossa principal questão é: como certas coletividades vêm conseguindo construir instrumentos para efetivar sua cidadania, diante das forças ligadas ao Estado ou ao mercado?

A pesquisa pretende identificar o diálogo específico travado pelas populações locais, entre os seus próprios segmentos e com outros atores sociais, no contexto dos processos relativos às transformações que os espaços denominados rurais ${ }^{\mathrm{v}}$ vêm sofrendo na sociedade contemporânea globalizada. Busca compreender a percepção dessas populações, quanto ao que consideram ser “direito", "participação" e "cidadania”, considerando suas práticas participativas na gestão das APAs em estudo, sobretudo nos seus Conselhos. Almeja, assim, contribuir para a reflexão sobre os processos envolvidos na instituição coletiva de um projeto de gestão democrática, em que os “cidadãos autônomos" sejam capazes de deliberar sobre seu destino comum e reorientar os rumos 
assumidos pelas relações entre si e com o seu ambiente, na busca da cons trução de uma sociedade socioambientalmente mais justa.

A investigação busca identificar os processos sociais que sustentam os significados envolvidos no campo da gestão ambiental, adotando os métodos bibliográfico, documental, etnográfico e histórico e orientada por uma abordagem processual e sistêmica do ambiente, considerado em sua complexidade ${ }^{\mathrm{vi}}$, relatividade e historicidade, segundo diferentes escalas (local, regional, estadual, nacional, global). O ambiente é visto como um sistema em contínuo processo de construção pelas interações entre os atores, que produzem respostas ativas às circunstâncias impostas pelas pressões sociais, podendo questionar e recriar certas orientações e significados dominantes, adequando-os ao seu contexto, num fluxo constante de ressignificações.

O conceito de cidadania ambiental ${ }^{\mathrm{vii}}$, inicialmente adotado, foi se revelando limitado, insuficiente para se compreender a complexidade das relações envolvidas no processo de gestão ambiental; assim como o próprio conceito de cidadania, se assumido de forma essencializada e tomando como modelo de valoração as tradições históricas da construção da cidadania nos países considerados centrais ${ }^{\text {viii }}$, desconsiderando as características específicas assumidas pela "cidadania à brasileira".

Desta maneira, a partir do processo de implantação das APAs em estudo, esse artigo apresenta algumas reflexões sobre a temática da cidadania, pretendendo questionar certas concepções fortemente arraigadas no senso comum e no discurso político, que desqualificam a “cidadania à brasileira”. Defende a necessidade de um enfoque diferenciado em relação às práticas características da "cultura política brasileira", tais como o clientelismo, a troca de favores, o patrimonialismo, identificadas na análise de muitos cientistas sociais brasileiros, como “imperfeições", “desvios” em relação ao padrão ocidental moderno de construção da democracia e da cidadania. Busca compreendê-las como práticas de cidadania diferentes do modelo normativo dos países centrais, pois são maneiras específicas dos diversos atores sociais, muitas vezes em posição desvantajosa no contexto das relações de poder, encaminharem seus interesses e fazerem valer seus direitos, no contexto da experiência histórica de construção da democracia brasileira, com as particularidades de uma sociedade semiperiférica ${ }^{\text {ix }}$, marcada por um Estado autoritário.

A compreensão dos diversos sentidos que a cidadania pode assumir para os múltiplos atores envolvidos é nuclear para o êxito da implantação das UCs, pois sua gestão deve se basear em mecanismos democráticos baseados na participação e no controle dos cidadãos. 


\section{CARACTERIZAÇÃO DA REGIÃO EM ESTUDO: A BACIA HIDROGRÁFICA DO RIO MACAÉ}

Localizada na faixa costeira central-norte do Estado do Rio de Janeiro, a Bacia Hidrográfica do Rio Macaé é a maior bacia exclusivamente estadual, em termos de extensão $\left(1765 \mathrm{~km}^{2}\right)$. Ela abrange seis municípios, com destaque para Nova Friburgo, onde se localizam as nascentes do rio Macaé, e Macaé, onde o Rio Macaé desemboca no Oceano Atlântico, junto à cidade de Macaé, após percorrer $136 \mathrm{~km}$.

A gestão dessa Bacia envolve grande complexidade, por abranger vários municípios, com diversas realidades políticas, sociais e econômicas, bem como diferentes ecossistemas: a área serrana, onde se situam as nascentes do rio principal, que apresenta, então, leito pedregoso e percorre terrenos rochosos e acidentados, e as áreas de planícies aluvionais costeiras, onde seu leito se apresenta arenoso, com as margens baixas e espraiadas e parte do curso retificado, provocando freqüentes enchentes e inundações na época das chuvas, durante o verão, e um período de seca, durante o inverno. Nela estão presentes diversos tipos de usos do solo: a área serrana dedica-se, sobretudo, à agricultura familiar e ao turismo e começa a sofrer intenso processo de ocupação descontrolada, enquanto que na zona de planícies costeiras e estuarina predominam as áreas urbanas e industriais, mais populosas e com maior poder econômico e político.

A partir dos anos 1970/1980, a região vem passando por transformações decorrentes, principalmente, dos processos de desenvolvimento do turismo, da urbanização e da industrialização, que estão provocando o crescimento populacional e sua degradação socioambiental. Na parte baixa da Bacia, os processos de industrialização e de urbanização se intensificaram com a instalação da Petrobrás, em 1978. Segundo a Prefeitura Municipal de Macaé (PMM) ${ }^{\mathrm{x}}$, no município se concentram $85 \%$ da produção de petróleo brasileira e $47 \%$ da produção nacional de gás, extraídos da bacia de Campos, além de indústrias ligadas ao setor offshore. Há, também, duas usinas termelétricas (UTE) movidas a gás natural, que foram implantadas, no início dos anos 2000, no contexto da crise energética, de acordo com plano do governo federal: a UTE Norte Fluminense, pertencente ao Grupo EDF (Eletricité de France) ${ }^{\mathrm{xi}}$ - maior gerador de energia elétrica do mundo (90\% do seu capital) - e à Petrobrás (10\%), e a UTE Macaé Merchant, implantada, em 2001, pela empresa transnacional El Paso e vendida, em 2006, para a Petrobrás, passando a chamar-se UTE Mário Lago Ltda ${ }^{\text {xii }}$.

Todas essas empresas, ligadas ao setor energético envolvem interesses globais e utilizam as águas do Rio Macaé em seus processos produtivos, as quais também são usadas para irrigação das lavouras, para o lazer e prática de esportes, dessedentação dos animais e para o abastecimento de milhares de pessoas, nos municípios de Casimiro de Abreu, Macaé e Rio das Ostras. 
As APAs em estudo foram criadas para preservar as nascentes do rio Macaé e apresentam grande riqueza em termos de recursos hídricos e de biodiversidade. Elas integram o Corredor Central da Mata Atlântica ${ }^{\text {xiii }}$, na Serra do Mar, na Reserva da Biosfera da Mata Atlântica ${ }^{\text {xiv }}$. A Mata Atlântica é considerada um bioma prioritário para a conservação, um dos mais ricos do mundo em biodiversidade; no entanto só restam menos de $8 \%$ de sua cobertura original. Em sua área de abrangência original vivem 120 milhões de brasileiros, que dela dependem para obter água e condições climáticas adequadas, bem como são gerados $70 \%$ do Produto Interno Bruto do País ${ }^{\text {xv }}$.

Remanescentes da Floresta Ombrófila Densa primária ainda podem ser encontrados nas altitudes mais elevadas das serras existentes nas terras drenadas pela bacia hidrográfica do rio Macaé, preservados pelas dificuldades de acesso e de ocupação. No entanto, boa parte da mata lá existente não é mais primária, mas apresenta diversos estágios de sucessão, sendo fruto de um longo processo histórico de manejo de espécies vegetais e animais, pelas populações que vêm habitando esse território, principalmente a partir dos anos 1820. A região, então, recebeu colonos suíços, devido ao fracasso do projeto oficial de colonização na Fazenda do Morro Queimado, origem da atual cidade de Nova Friburgo. Em 1824, para lá também se dirigiram colonos alemães.

Este projeto começou em 1818, quando o Rei Dom João VI e o governo da Suíça firmaram um acordo, objetivando substituir a mão de obra escrava por imigrantes livres ${ }^{x v i}$, no Brasil, e desafogar as pressões do excesso de mão de obra na sociedade européia. Diante das inúmeras dificuldades encontradas no núcleo de povoamento oficial, famílias de colonos se deslocaram para o Leste, acompanhando o Vale do Rio Macaé, em busca de terras mais quentes e propícias ao cultivo do café. Foram, então, fundados vários povoados, como Lumiar, São Pedro da Serra, Cascata, Sana. Ao contrário do Sul do Brasil, os imigrantes não mantiveram suas matrizes culturais e foram adotando o modo de viver dos brasileiros; viviam cercados por fazendeiros escravocratas e cafeicultores, numa situação inicialmente de relativa pobreza, e sobreviveram recorrendo aos métodos de cultivo nativos. Desenvolveram uma pequena e média agricultura de base familiar, dedicada ao cultivo do café e dos produtos de subsistência, como o feijão, mandioca, hortaliças e a criação de animais.

Devido à decadência do café, nos anos 1930/40, muitas áreas antes produtivas foram abandonadas, permitindo seu reflorestamento, ou foram transformadas em pastagens, principalmente nas áreas de menor declividade, como o Sana, onde também se desenvolveu a monocultura de banana. A abertura de estradas de terra, no fim dos anos 1950, facilitou o acesso aos centros urbanos, antes feito por trilhas em cavalos ou burros. Os distritos de Lumiar e São Pedro da Serra, na APA de Macaé de Cima, em Nova Friburgo, aliaram a produção de subsistência à venda de produtos como inhame, banana, tomate, pimentão, para os centros urbanos próximos, numa 
região que, até os anos 1980, era incluída no chamado "cinturão verde" do Rio de Janeiro , conforme mencionado por Musumeci (1987).

O relativo isolamento foi rompido, em Nova Friburgo, nos anos 1980, pela pavimentação asfáltica da rodovia RJ-142, trecho Muri-Lumiar, e pela eletrificação da maior parte da região; no Sana, pela construção da Ponte da Amizade, em 1987. Em 2006, o trecho Lumiar-Casimiro de Abreu da rodovia RJ-142 - Estrada Serramar - foi asfaltado. A melhoria das condições de acesso estimulou o desenvolvimento turístico. Instaurou-se, então, em toda a região, acelerado processo de transformações sociais, econômicas, culturais e espaciais. Além dos turistas, chegaram novos moradores, fugindo dos centros urbanos e em busca de "formas alternativas" de vida. As atividades agropecuárias foram sendo substituídas por atividades ligadas ao turismo, à construção civil, à prestação de serviços e ao comércio, como principais fontes de renda para seus antigos moradores, que, "de lavradores se tornaram cortadores de grama"xvii. Muitos agricultores procuraram combinar as atividades tradicionais com as novas oportunidades de renda e trabalho, constituindo unidades familiares que se caracterizam pela pluriatividade ${ }^{\mathrm{xviii}}$.

Os processos de ocupação e de uso do solo foram redefinidos: a especulação imobiliária provocou a fragmentação das propriedades e uma transferência parcial da propriedade da terra. Muitos imóveis alteraram suas funções agrícolas para se tornarem residências, sítios de veraneio ou pousadas; viraram locais de consumo e de "contemplação da natureza", em vez de produção, gerando novos valores e configurações territoriais. Desenvolveu-se um outro modo de regulação das formas de consumo da natureza, associado ao espaço rural: um usufruto 'desinteressado', informado pela sensibilidade artística ou pela compreensão científica ${ }^{x i x}$, muitas vezes conflitante com os valores tradicionais locais. Configuraram-se, assim, novas "ruralidades" e outras concepções sobre o "rural", que não é mais necessariamente agrícola ou local de produção, mas local de consumo e de contemplação de uma paisagem "natural" que deve ser preservada.

Os processos de diferenciação e hierarquização social se acentuaram em localidades antes marcadas por relações de parentesco ou vizinhança. Constituíram-se novos ordenamentos nas relações sociais, expressos por mudanças nos modos de ser, viver e pensar de suas populações locais originais: pequenos produtores rurais, cuja identidade era garantida pelo compartilhamento de um modo de viver e que, atualmente, é construída pela e na interação com os turistas, com os novos moradores, com os agentes das instituições e os meios de comunicação do mundo urbano industrial. Foram introduzidos hábitos, conhecimentos e valores, que passaram a interagir com os valores, costumes e saberes locais. Formaram-se dois grandes grupos, segundo a percepção local: os "de fora" e os "do lugar" ou "da terra" (ou "nativos", como se diz no Sana), cujas interações envolvem diferentes padrões de relações sociais, desde o conflito aberto à convivência profícua e respeitosa, que proporciona troca de saberes e crescimento mútuo. 
Também aumentaram os impactos ambientais em áreas já degradadas por técnicas agropecuárias baseadas na queimada, no cultivo e na criação de animais em encostas e margens dos rios e no uso indiscriminado de agrotóxicos. Intensificaram-se os desmatamentos para construção de imóveis e abertura de estradas, agravando os processos erosivos e o assoreamento dos cursos d'água, crescentemente poluídos com esgotos domésticos.

Por outro lado, a importância dos recursos hídricos e da biodiversidade da região, considerada de alta sensibilidade ambiental às alterações de uso e cobertura, despertou o interesse de organizações não-governamentais ambientalistas, de governos e grandes empresas, pro vocando a introdução de várias novas regulamentações exteriores, relacionadas à "preservação ambiental" e ao "desenvolvimento sustentável". O discurso ambientalista, veiculado pelos "novos moradores" e pelos meios de comunicação, ganhou destaque. Além disso, a partir dos anos 1990, os órgãos públicos ambientais passaram a intensificar a fiscalização e a multar, principalmente, os pequenos agricultores, muitas vezes de forma agressiva e autoritária, segundo relatos locais. Em 2001, foram criadas as APAs em estudo, sem haver esclarecimento nem consulta às populações locais, conforme determina a legislação. As novas regulamentações, valores e conhecimentos voltados para a preservação ambiental em interação com as tradições culturais locais vêm provocando o surgimento de intensos conflitos relativos aos múltiplos e diferenciados interesses e usos dos recursos naturais pelos diversos grupos envolvidos e, contraditoriamente, muitas vezes, geram efeitos contrários aos desejados, pois provocam rejeição e resistências à temática ambiental.

\section{O PROCESSO DE AMBIENTALIZAÇÃO DA SOCIEDADE E A CRIAÇÃO DAS APAS EM ESTUDO}

Nas últimas décadas do século XX, diante da chamada "crise ambiental global", instaurouse o processo de ambientalização ${ }^{\mathrm{xx}}$ da sociedade: a problemática ambiental foi se tornando uma questão pública mundial, foco de preocupação de movimentos sociais e organizações nãogovernamentais, das empresas, dos governos, dos meios de comunicação. Foram criados organismos institucionais, como Ministérios do Meio Ambiente, instaurando e difundindo novos valores, atitudes e regulamentações voltados para a "preservação ambiental" ou para "promover o desenvolvimento sustentável", através da criação de ordenamentos jurídicos e de instrumentos de imposição de condutas e de padrões morais, como algumas práticas de Educação Ambiental.

Nesse contexto, em termos mundiais, a criação de áreas protegidas tem sido vista como um dos principais meios de conservação da biodiversidade in situ. No Brasil, após longo e polêmico período de tramitação no Congresso Nacional, foi instituído o Sistema Nacional de Unidades de Conservação da Natureza (Lei do SNUC, Lei 9.985/2000), estabelecendo diversas categorias de 
Unidades de Conservação da Natureza (UCs), cuja gestão deve ser democrática e baseada na participação popular, por meio de conselhos, com caráter consultivo ou deliberativo, conforme a categoria de UC. A Lei do SNUC obedece aos princípios de gestão democrática, participativa e descentralizada, instituídos pela Constituição Federal de 1988, elaborada no período de redemocratização da sociedade brasileira, influenciada por diversos movimentos sociais que visavam incluir os cidadãos nos processos de discussão, decisão e controle das políticas públicas.

No entanto, sob outro prisma ideológico, a partir dos anos 1980/90, no contexto da Globalização e do neoliberalismo, os organismos internacionais multilaterais, como o Banco Mundial, condutores do processo planetário de expansão capitalista, desenvolveram novos instrumentos de regulação social, a partir do "fracasso" das experiências socialistas e da eclosão dos movimentos sociais. Difundiram a necessidade de reforçar a participação popular nas arenas decisórias, através da criação de órgãos baseados numa nova relação governo-sociedade, desenvolvendo mecanismos de democracia participativa para complementar os da democracia representativa. Instituíram novo tipo de relação governo-sociedade, com um "Estado Mínimo", criando instrumentos de "governança" local, construindo "parcerias", dividindo responsabilidades e criando instrumentos de participação "concedida"xxi, para promover o "envolvimento" e o "empoderamento" das populações, vistas como "stakeholders", "parceiras", em projetos públicos e privados. Esse discurso é central para a construção de propostas voltadas para a promoção de estratégias de "desenvolvimento local sustentável”, em especial no caso das áreas rurais ${ }^{x x i i}$, financiadas com recursos das agências internacionais, como o Banco Mundial, como ocorre nas APAs em estudo.

Ambos os discursos - um de cunho mais "social" e o outro, "neoliberal" - orientam a implementação de políticas públicas baseadas em instrumentos participativos, com destaque para o campo da política ambiental; usam expressões como participação social, controle social, empoderamento, sociedade civil, cidadania, direitos, entre outras, que podem assumir significados distintos, ligados aos diversos projetos individuais ou coletivos, conforme a situação.

No contexto do SNUC, a categoria APA está destinada a funcionar como zona de amortecimento de UCs de proteção integral e como corredor ecológico. É um tipo de UC que permite diferentes usos sustentáveis do território, mantendo a propriedade privada dos imóveis. Muitos ambientalistas preservacionistas ${ }^{\mathrm{xxiii}}$ questionam sua eficácia, pois nela coexistem terras públicas e privadas. Assim, seu sucesso depende da consciência individual dos proprietários e da capacidade do Poder Público para garantir o ordenamento e a fiscalização do território. Teoricamente sua criação aumentaria a extensão das áreas protegidas. Segundo Cozzolino (2005, p.43), no Brasil, a categoria APA é a UC de uso sustentável que ocupa maior extensão de área coberta. 
A transformação de uma região em UC implica uma alteração das formas de apropriação simbólica da natureza e a introdução de novos usos sociais do espaço. Para Barreto (2001), uma UC é um "artefato cultural", um "construto socionatural", "instável e indeterminado", definido num dado contexto histórico, a partir de uma correlação de forças, orientada por critérios técnicocientíficos e políticos dominantes. É uma regulamentação que impõe a visão do Estado (mais moldada pelas populações urbanas) de natureza e de ambiente, estabelecendo normas para o uso de certas áreas, diante de sua atribuída função ambiental, em nome da defesa de um "patrimônio coletivo". Esta visão pode entrar em choque com as necessidades e saberes locais, desqualificar as formas tradicionais de relação com a natureza e buscar substituí-las por outras, desconsiderando, inclusive, o papel das populações rura is na formação dessa "natureza" e sua visão da terra como um espaço produtivo, de obtenção da sobrevivência. Isso aconteceu nos casos em estudo, assim como em muitas outras áreas protegidas no Brasil e no mundo, criadas por iniciativa do Estado, sem considerar os direitos dos cidadãos que lá viviam.

\section{A CIDADANIA NAS APAS EM ESTUDO}

Nos dois casos, o processo de criação e implantação das APAs ocorreu por meio de uma aliança entre os representantes do Poder Público e alguns "novos moradores", participantes do movimento ambientalista e defensores dos valores de preservação da natureza. Por outro lado, inicialmente, houve certa exclusão dos grupos ligados à pequena produção rural, antigos moradores da região, que tiveram que lutar para serem ouvidos, em nome de seus "direitos", enquanto “verdadeira população do lugar". No decorrer do processo, no caso da APA do Sana, os produtores rurais foram se afastando, apesar de muitas associações se denominarem representantes desses setores. Mas eles passaram a procurar aproveitar as oportunidades em termos de geração de renda, surgidas com o desenvolvimento do turis mo e com o advento de recursos para serem aplicados em projetos ambientais.

Já na APA de Macaé de Cima, o conflito foi bem mais intenso: os agricultores assumiram a identidade de "população tradicional"; passaram a lutar em defesa do "direito de decisão" em relação às suas propriedades e ao território por eles ocupado há muitas gerações, garantia da reprodução de sua condição de produtores rurais. Ao longo do processo de luta contra a implantação da APA, estes agricultores foram se constituindo enquanto novos atores políticos, acionando aquelas que geralmente são consideradas práticas ativas de cidadania ${ }^{x x i v}$. Organizaram movimentos reivindicatórios junto aos representantes políticos dos legislativos municipais e estaduais; criaram um movimento social - a "União das Famílias da Terra (UFT)”, que se autoproclama a "a voz da população tradicional" em adesivos e em placas afixadas em vários 
pontos das estradas; moveram ação junto ao Ministério Público contra o governo estadual e acionaram seus representantes na Assembléia Legis lativa. Desta maneira, conseguiram suspender o processo de implantação da UC, tal como vinha sendo conduzido pelo órgão gestor estadual e buscaram adequá-lo a sua perspectiva. Eles promoveram uma indigenização ${ }^{\mathrm{xxv}}$ do discurso político e ambiental global dominante: alegam que seu modo de viver e de trabalhar foi responsável pela existência até hoje das matas na região, se apresentando como os "verdadeiros ambientalistas", em contraposição aos que se dizem "protetores da natureza", mas que, segundo eles, degradam o ambiente, com abertura de platôs, a construção de piscinas naturais e de jardins gramados nas margens dos rios, "para aumentar o seu conforto e não para garantir sua sobrevivência", como eles. Da sua perspectiva, "garantiram a preservação da mata, enquanto o resto do mundo destruía" e não compreendem porque agora "estão sendo penalizados por isso" e desejam "poder viver em paz", "poder trabalhar como sempre", segundo falas locais. Sua luta serviu para defender indiretamente os interesses ligados à especulação imobiliária e à construção civil, que também ficaram descontentes com a criação da APA - mas cuja causa não encontra tanta simpatia e apoio - e foram intensificadas por divergências partidárias entre os ocupantes dos governos estadual e municipal; inclusive foi um dos principais temas na disputa eleitoral local para a Câmara dos Vereadores de Nova Friburgo, em 2008. A atuação da UFT negou, desta maneira, uma visão disseminada no senso comum, no campo científico e nos órgãos públicos, que considera as populações "rurais" alienadas, "conformistas", alheias à participação, ocupando uma posição de marginalidade, nos quadros de uma visão evolucionista modernizadora.

É interessante observar que os pequenos produtores acionaram a categoria "rural" ", como suporte de sua identidade, definidora de seu lugar próprio no mundo social. Aliada a ela, a identidade de "populações tradicionais" xxvi assumiu, nos casos em estudo, principalmente no caso da APA de Macaé de Cima, uma dimensão política estratégica, no processo de confronto e luta deste grupo pela construção e afirmação de sua posição pública, específica, em oposição à sociedade mais ampla. Eles procuraram obter seu reconhecimento oficial como uma "população tradicional", o que lhes garantiria "direitos" no uso de suas propriedades, segundo as novas leis de inspiração socioambiental. Se eles são realmente ou não "populações tradicionais" não é o cerne da questão, já que esta é uma identidade auto-atribuída, conforme a legislação; o importante é seu significado político. Além disso, corre o risco de ser associada a concepções de imobilidade histórica e de atraso econômico, podendo "congelar" as características desses grupos. É importante ressaltar que todas as populações estão num processo contínuo de mudanças, decorrente da própria dinâmica social e provocado por sua crescente interação com outros grupos e instituições, em que as "tradições" vão sendo renovadas cotidianamente. 
A observação das práticas ativas dos agricultores da UFT, grupos geralmente vistos como "passivos", "ignorantes", fizeram com que o enfoque da investigação se deslocasse: de uma concepção inicial de verificar a existência de uma "maior" ou "menor" cidadania, como se fosse uma questão de mensuração, ficou evidenciada a necessidade de se focalizar a multiplicidade de sentidos referentes ao que os diferentes atores consideram ser seus "direitos de cidadão", em circulação nas práticas de cidadania envolvidas no processo de definição dos rumos do processo de desenvolvimento local. Todos acionam as categorias "direito" e "cidadão" enquanto instrumentos de luta política e de defesa de seus interesses, apesar de que a concepção dominante afirma que "o direito é o que está na Lei”, conforme disse militante do movimento ambientalista e ardorosa defensora da APA do Sana. No entanto, muitas vezes, o que está estabelecido na Lei é bem diferente e distante da realidade complexa; ou, então, a garantia de certos direitos legais relativos a diferentes atores pode afetar os interesses legais de outros atores.

O conceito de "cidadania ambiental" inicialmente assumido como conceito direcionador da investigação, mostrou-se problemático, pois a observação das práticas cotidianas de participação evidenciou a relatividade dos significados envolvidos em termos como "vigiar e participar na instrumentação das políticas públicas", "projeto próprio", "manipulação de recursos naturais mais racional e equitativa", "entorno mais habitável", cujos sentidos dependem dos interesses e dos valores que orientam as interações cotidianas dos atores humanos envolvidos no processo de construção do ambiente. Por exemplo, o que se considera como "habitável" varia bastante conforme as condições sociais e econômicas e históricas e o "projeto próprio" pode não ser necessariamente adequado aos interesses coletivos. Além disso, a visão de "manipulação dos recursos naturais mais racional" evidencia a manutenção de uma concepção de ambiente, baseada numa visão dicotômica, que separa a "natureza" da "cultura/sociedade, conforme a tradição racionalista antropocêntrica ocidental, instaurada a partir da Idade Moderna, no contexto de implantação do Capitalismo, base da crise ambiental contemporânea.

Outra grande "tradição" da modernidade é o termo cidadania, que assume significados variáveis ao logo do tempo, do espaço e dos grupos que o utilizam. O conceito foi criado na Antiguidade, quando os cidadãos se reuniram para deliberar com autonomia sobre os destinos da polis grega, inventando a democracia: sistema político então baseado na participação direta dos cidadãos e sustentado pela escravidão da maioria da população. No século XVIII, no contexto das Revoluções Burguesas, a concepção de cidadania da Antiguidade foi redefinida em três aspectos:

-A construção do Estado, com seu conjunto de instituições políticas, como instância separada da sociedade civil, atingindo territórios e populações maiores. O princípio republicano romano foi recuperado pela burguesia, que estabeleceu o controle popular pelo sufrágio universal, 
segundo a visão de soberania popular: o cidadão exerce seu poder através de seus representantes, escolhidos pelo voto.

- A adoção do regime democrático de governo e da igualdade jurídico-política de participação.

- A definição dos direitos humanos, inexistente na Antiguidade marcada pela escravidão.

As diversas tradições de pensamento da Modernidade elaboraram distintas concepções de cidadania, mas a visão liberal se tornou dominante no discurso jurídico e administrativo dos Estados Nacionais, desenvolvido, principalmente no século XIX, e que vinculou a cidadania ao espaço territorial da nação. Nela, a cidadania envolve o pertencimento igualitário a uma dada comunidade política - o Estado Nacional - e consiste em direitos, deveres e instituições para garantir a eficácia social e política. Orientada pela distinção entre Estado e sociedade civil (campo das livres associações dos indivíduos), afirma a primazia do indivíduo perante o Estado e defende os princípios da propriedade e da liberdade.

No caso das APAs em estudo, os direitos à propriedade e à liberdade para decidir sobre os usos de suas terras são constantemente invocados, tanto pelos "novos moradores" "a mbientalistas", quanto pelos "pequenos produtores rurais", sendo um dos argumentos centrais do discurso dos últimos contra a implantação destas UCs. Ou pela criação de um outro tipo de UC como pode ser nitidamente observado, no caso da APA de Macaé de Cima, onde moradores, proprietários e agricultores da localidade de Macaé de Cima estão reivindicando a criação do Refúgio de Vida Silvestre Municipal Flores-Macaé de Cima (RVS-Floma), na região das cabeceiras do Rio Macaé, correspondente ao território da APA Municipal de Macaé de Cima e parte do Parque Estadual de Três Picos (PETP). Eles vêm lutando por alternativas legais para garantir sua permanência no local, pertencente ao PETP. Embora tanto a categoria RVS quanto Parque sejam UCs de Proteção Integral, a primeira permite a manutenção das propriedades privadas em seu interior, enquanto a segunda exige a desapropriação obrigatória em todos os casos. Nesse caso, está ocorrendo uma aliança entre os "novos" e os "antigos" proprietários em defesa do seu direito fundamental de propriedade e de sua permanência no local.

Durante o trabalho de campo, foi observado, em diversas situações, como os diferentes atores envolvidos no processo de gestão das APAs em estudo acionavam as categorias "direitos" e "cidadania" para legitimar seus interesses e justificar suas ações. Frequentemente, os direitos acionados por um certo grupo podem entrar em choque com os direitos reivindicados por outros atores, como, por exemplo, "o direito a um ambiente saudável e equilibrado", reivindicado pelos "novos moradores ambientalistas" e o "direito à propriedade" "ao trabalho" e "à sobrevivência", reivindicado pelos pequenos agricultores, diante das limitações impostas pela legislação ambiental ao desenvolvimento das suas atividades costumeiras, como as queimadas. 
De qualquer maneira, a cidadania envolve uma dimensão simbólica, relacionada a valores e significados socialmente estabelecidos; refere-se à identidade social dos indivíduos, formada por suas interações com o Estado e com os outros atores sociais. Mesmo em tempos de globalização capitalista, cada sociedade nacional estabelece critérios para definir quem é o cidadão e quais são os seus direitos e deveres perante a coletividade, bem como criar as instituições que viabilizam as práticas dessa cidadania e as relações dos cidadãos entre si e com o Estado. Para Santos (2003, p.240), a cidadania, por um lado, limita os poderes do Estado e, por outro, "universaliza e igualiza as particularidades dos sujeitos de modo a facilitar o controle social de suas atividades e, consequentemente, a regulação social”.

Com o desenvolvimento capitalista, a representação democrática tornou-se manipulada pelos interesses corporativos poderosos e os cidadãos foram se afastando dos mecanismos tradicionais de representação e criando novas formas de solidariedade e de instituições, como as organizações não-governamentais (ONGs). Segundo Vieira (2002), no mundo contemporâneo, configura-se uma tendência para a constituição de uma sociedade civil global e de uma cidadania mundial como contraponto à tendência de relativo enfraquecimento do Estado nacional. Ele defende a necessidade da constituição de uma cidadania local e planetária, capaz de estabelecer conexões entre a melhoria da qualidade de vida no ambiente cotidiano e o enfrentamento das ameaças globais, de influir tanto nas decisões locais quanto globais.

A participação das populações locais na gestão das UCs, por meio de seus conselhos é um tipo de participação concedida que pode influir tanto em decisões relativas a problemas locais quanto globais e envolve questões fundamentais como: Qual é a importância das decisões de que se participa? Qual é o grau de controle dos membros sobre a execução das decisões tomadas? Até que ponto esta participação possibilita o fortalecimento da cidadania e da autonomia dos envolvidos ou se torna um instrumento regulatório e de legitimação das políticas públicas?

\section{A PARTICIPAÇÃO NOS CONSELHOS DAS APAS EM ESTUDO}

A observação das condições e dos conflitos evidenciados pelo funcionamento dos Conselhos das APAs em estudo revela a complexidade do potencial (regulatório e/ou emancipatório) destes órgãos enquanto espaços de desenvolvimento de práticas participativas de cidadania.

Os Conselhos das UCs são instrumentos que visam construir novas instâncias de poder e estabelecer um certo tipo de relação entre o Poder Público e as populações locais através de suas entidades representativas, para ordenar os usos do espaço e dos recursos naturais.

A composição original do Conselho da APA estadual de Macaé de Cima foi definida pelo decreto $n^{\circ} 38234 / 2005$ e incluía, principalmente, entidades externas à região; era presidido pelo 
órgão gestor estadual, a extinta Fundação Estadual de Engenharia e Meio Ambiente (FEEMA) ${ }^{\mathrm{xxvii}}$. Em 2007, o novo governo estadual introduziu a gestão compartilhada das UCs estaduais entre a FEEMA e o Instituto Estadual de Florestas (IEF). Diante da situação encontrada de desarticulação e esvaziamento dos conselhos das UCs, a Diretoria de Biodiversidade do IEF, inspirada pelas concepções socioambientalistas, iniciou o Programa de Fortalecimento dos Conselhos das UCs, inserido no Programa de Proteção à Mata Atlântica, visando criar novos conselhos ou recompor os já existentes, nas diversas UCs estaduais.

Neste contexto, durante o segundo semestre de 2007, o IEF realizou oficinas nas várias UCs estaduais visando recompor seus Conselhos. No caso da APA de Macaé de Cima, os membros da UFT se recusaram a participar das oficinas e esta ausência só os fortaleceu, pois seus anseios e reivindicações foram referências sempre presentes durante os trabalhos. Inicialmente, os agricultores não quiseram formalizar seu movimento, transformando a UFT numa associação oficial, mas aproveitavam a estrutura da Ação Rural de Lumiar, instituição ligada à Igreja Católica, para viabilizar sua organização e comunicação. No entanto, no final de 2008, ao perceberem que suas diversas ações para "acabar" com a APA não tinham surtido efeito e que a criação do no vo Conselho ocorreria, independente da presença deles ou não, resolveram registrar a entidade e incentivar a formação de outras associações de moradores, nas diferentes localidades incluídas no território da APA. Em Abril de 2009, foi publicada a Portaria INEA/PRES no 35/2009, definindo a composição do novo conselho consultivo da APA de Macaé de Cima, formado por 42 entidades, com forte representação local. A posse do Conselho ocorreu em Maio de 2009 e, em Julho, foi iniciada a elaboração do Regimento Interno, aprovado em Setembro de 2009. Somente agora, o Conselho começa a se reunir periodicamente e é importante observar como serão suas condições de funcionamento, com um número tão grande de entidades.

Assim que a APA do Sana foi legalmente instituída, em 2001, os "novos moradores", principalmente, começaram a pressionar pela criação do Conselho Gestor e fundaram diversas associações e entidades para dele participarem. A primeira reunião do Conselho Gestor da APA do Sana (oficializado pelo Decreto municipal 075/2002) foi em Outubro de 2002. A implantação desta UC encontra-se num estágio bem consolidado: seu Conselho Gestor, o SANAPA, é composto por uma Plenária paritária, atualmente formada por 6 representantes do Poder Público e 6 da sociedade civil, com caráter deliberativo, presidido pelo Secretário Municipal de Meio Ambiente; possui um Plano de Manejo, pequena sede própria e uma secretaria executiva, nomeada pela Prefeitura Municipal de Macaé (PMM) e aprovada pela Plenária. Conta com Câmaras Técnicas, criadas a partir de demandas governamentais ou da comunidade e também técnicos e pessoas da comunidade; seu Regimento Interno está em fase de revisão. 
Nas reuniões bimestrais do Sanapa, é possível observar a existência de conflitos decorrentes do confronto entre diferentes valores e interesses (turismo, agricultura, preservação ambiental) e a ocorrência de práticas tradicionais, características da chamada cultura política brasileira, reatualizadas em contexto de política ambiental e em nome do que se propõe a ser uma gestão participativa. Analisando o caso da APA do Sana, Cozzolino (2005) e Gaspar (2009) afirmam haver grande controle da população e dos militantes das ONGs por práticas clientelísticas desenvolvidas pelas lideranças políticas do Poder Executivo e Legislativo, sendo a mais corrente sua cooptação através da colocação na folha de vencimentos da PMM ou o financiamento de projetos ambientais e sociais. Por sua vez, os Conselheiros se tornam novos agentes de intermediação da população com o Poder Público, os políticos e o acesso aos serviços básicos, rompendo com as relações de poder dominadas por alguns grandes proprietários de terra, mas, muitas vezes, reproduzindo as práticas políticas tradicionais.

A busca do controle da participação popular nos diversos fóruns e conselhos públicos, por práticas clientelísticas, pelo patrimonialismo e pela defesa dos interesses privados é mais uma manifestação do autoritarismo do Estado, traço cultural e estrutural da sociedade brasileira. A permanência destas práticas é vista, tanto pelo senso comum como pe las Ciências Sociais, como impedimento para a emergência de instituições democráticas mais sólidas e a construção de uma cidadania combativa $^{\text {xxviii }}$, conforme visão essencializada sobre o que vem sendo chamado de "cultura política brasileira". Tavolaro (2009), ao analisar criticamente a produção sociológica nacional sobre a "cidadania à brasileira", a firma que esta assume como padrão o modelo histórico da ordem normativa das sociedades modernas centrais. São abordagens que visam verificar até que ponto, no Brasil, a institucionalização das garantias, obrigações e direitos civis, políticos e sociais se afastou desse modelo e propõem a existência de um "desvio normativo brasileiro", responsável pela manutenção do caráter elitista da democracia brasileira, marcada pelo desrespeito aos princípios liberais fundamentais e pela sedimentação de estruturas patrimonialistas. Adota-se uma visão dualista, em que o tradicional se caracteriza pela ausência de instituições modernas, para regular o poder dos políticos e dos funcionários públicos, e o moderno significa a predominância de procedimentos legal-racionais na administração pública, por meio de instituições políticas representativas e comprometidas com o "bem comum" e a universalização dos direitos.

Estas análises não veem possibilidades de examinar o espaço que se abre entre os pontos de referência 'tradicional' e 'democrático' e como essas práticas podem se transformar no contexto dos novos espaços participativos. Ottmann (2009) questiona a noção de que a persistência das práticas políticas tradicionais enfraquece a democracia no Brasil. Para ele, o processo de democratização tende a incorporá- las e a construir-se a partir delas, transformando-as cultural e materialmente; os atores envolvidos negociam suas demandas com seus intermediários e representantes. A cidadania 
brasileira, segundo o autor, seria uma "cidadania mediada", em que o acesso aos direitos é mediado por atores num contexto político que não se orienta por regras efetivamente universalistas, mas muitas alianças políticas são construídas através da barganha de cargos e vantagens pessoais, numa relação de dependência entre o patrono e seus clientes, que geralmente envolvem vários mediadores ou agentes. Como a mediação política é uma atividade competitiva, os eleitores fazem escolhas entre aqueles que lhes prometem os melhores retornos.

O interesse da Prefeitura Municipal de Macaé em criar a APA do Sana certamente está relacionado à aplicação de verbas oriundas de medidas compensatórias pela implantação de grandes empresas ligadas ao setor energético, no município de Macaé, usuárias dos recursos hídricos do Rio Macaé e portadoras de um discurso ecológico, sob a ótica capitalista. Por sua vez, as populações locais encaram os recursos investidos no lugar em projetos ambientais e sociais como uma espécie de "compensação" para os problemas decorrentes da transformação de seu lugar em UC. No entanto, se forem utilizados por representantes das entidades ou do poder público em proveito próprio, podem afetar a legitimidade institucional do Conselho e dos próprios instrumentos de gestão participativa, que passam a ser vistos como canais de promoção individual, como vem ocorrendo no Sana.

Segundo repetidas falas do Presidente do Sanapa, observadas em diversas reuniões, a PMM reconhece o Conselho como órgão deliberativo sobre as ações públicas e privadas que vão ser implementadas no Sana. Ele delibera sobre questões relativas ao saneamento básico, às obras públicas, aos serviços, como telefonia e transportes, ao calendário de eventos turísticos e os problemas dele decorrentes, como a poluição sonora e o uso de drogas, etc, por meio de debates acalorados e orientados pelos pareceres das Câmaras Técnicas. Dessa maneira, as decisões do SANAPA envolvem questões socioambientais, evidenciando a amplitude e a complexidade do campo da gestão ambiental que, além dos aspectos especificamente ligados ao meio físico e à biodiversidade, inclui relações sociais, econômicas, políticas e culturais. No entanto, muitas vezes, as decisões tomadas pelo Conselho não são respeitadas pelo Poder Municipal ou demoram muito tempo para serem efetivadas.

Um dos problemas em relação à atuação do Poder Público se refere à falta de integração entre as ações da Secretaria Municipal de Meio Ambiente, que ocupa a presidência do Sanapa, e as outras secretarias, acarretando indefinição das responsabilidades e atribuições dos envolvidos. Muitas vezes, decisões de um órgão podem entrar em choque com as de outros e com a proposta da APA. De uma maneira geral, interesses políticos e econômicos dominantes podem impedir ou favorecer a continuidade de certos projetos e ações, como, por exemplo, de fiscalização. O Conselho também pode favorecer a proeminência de certos atores, possibilitando-lhes maior visibilidade política e influindo, assim, nas disputas eleitorais. Uma das maneiras do Poder 
Municipal controlar o Conselho está na definição das regras para seleção das instituições componentes representantes do Poder Público e da sociedade civil. Outro problema refere-se à falta de autonomia financeira do Conselho, pois ele não conta com dotações específicas, mas depende de verbas de projetos e ações das diversas secretarias e órgãos públicos; assim, há sempre o risco do Poder Municipal tentar controlar o processo decisório. Por outro lado, as reuniões bimestrais do Sanapa exigiram a presença mais constante e efetiva dos representantes dos órgãos municipais no distrito, favorecendo a necessidade de prestação de contas diante das responsabilidades por eles assumidas nas reuniões anteriores.

Conforme Gaspar (2009) também constatou, a criação do Sanapa realmente instituiu uma nova instância de poder local, com a função de promover a reconfiguração do espaço e a regulação das atividades econômicas e usos do solo, a partir da definição de certos critérios de preservação ambiental. Lentamente os usos do solo e as atividades econômicas vão se adequando a esses critérios; porém muitas vezes, os pequenos empreendedores locais tem mais dificuldades para se adequar a eles, ocorrendo, assim, uma elitização e privatização do acesso aos recursos naturais e à renda gerada pelo turismo, mais dirigida para os "novos moradores". O cercamento das cachoeiras, poços e margens dos rios, que também ocorre na APA de Macaé de Cima, é uma evidência desse processo, impedindo o acesso de todos a áreas antes de uso coletivo.

A criação do Conselho da APA do Sana e a reestruturação do Conselho da APAMC provocaram a formação de novas associações, nas localidades envolvidas. Segundo Cozzolino (2005), no caso da APA do Sana, algumas dessas associações não têm atuação efetiva, mas foram criadas especificamente por indivíduos para ocupar um assento no Conselho, procurando flexibilizar as regras e legalizar suas atividades, para torná-lo um espaço de conquista de vantagens pessoais.

Há diferenças nas possibilidades e facilidades de participação entre os representantes do Poder Público e os das organizações da sociedade civil, que geralmente participam com base no trabalho voluntário. Também há diferenças quanto à linguagem utilizada, ao nível de instrução e ao acesso à informação entre os componentes da Plenária, tornando o diálogo entre os diversos atores um instrumento fundamental para aumentar a compreensão mútua das diferentes perspectivas em jogo, todos lutando pelo que consideram ser seus direitos de cidadania.

No entanto, nos dois casos analisados, encontra-se um pequeno grupo de pessoas e entidades participando ativamente do Conselho e dos diversos outros fóruns participativos que incidem sobre a região. Mas estas pessoas são praticamente as mesmas, nos diversos espaços, havendo pouca renovação dos quadros das lideranças das entidades. Enquanto isso, a maioria da população local, de certa forma, permanece alheia às reuniões e só se dá conta da existência da APA, quando esbarra em alguma regulamentação, ao desenvolver certas atividades. Uma das diferenças fundamentais 
entre as APAs estudadas reside na sua área de influência administrativa: uma é estadual, poder mais distante, e a outra é municipal, poder mais sujeito às pressões locais.

\section{CONSIDERAÇÕES FINAIS}

A democracia depende da participação - necessidade humana universal, inerente à própria vida em sociedade; é uma forma de existência social aberta, em contínua construção pela interação dos cidadãos organizados, que procuram desenvolver ações para expressar suas necessidades ou anseios, defender seus interesses, alcançar seus objetivos e influir nos poderes públicos. Envolve, assim, processos amplos e multifacetados, em que o conflito é considerado legítimo, permitindo a criação de novos direitos, daí apresentar potencial emancipatório.

A cidadania se constitui neste processo de luta pelos direitos. A partir do significado dominante da visão liberal, em que ser cidadão é a "condição do sujeito portador de direitos e deveres perante sua coletividade", na prática, a cidadania pode ir assumindo diferentes formas e conteúdos, sendo retraduzida pelos vários grupos, conforme suas posições sociais, tradições culturais e experiências históricas de participação social e política. Assim, o conceito teórico e a categoria política cidadania revelam-se extremamente complexos, diante dos seus múltiplos significados, assumidos em cada situação concreta, pois o que um determinado grupo/sociedade considera ser seu "direito", ou entende por "cidadania" e "participação", pode ser diverso da visão de outro. Basicamente, ser cidadão é participar plenamente da vida em sociedade e, inclusive, influir na construção do ambiente, que só existe para os seres que o habitam. Por sua vez, esse ambiente criado pelos atores humanos em interação com os não humanos, retroage sobre todos, estando num contínuo processo de reconstrução; ou seja, as ações humanas têm consequências que retornam sobre a própria humanidade, assim como sobre os ecossis temas.

Foi constatado, ainda, que muitos organismos, como conselhos e órgãos colegiados, baseados na participação popular, que buscam superar os limites da "democracia representativa" e construir uma "democracia participativa", podem, na verdade se constituir em instrumentos de controle da participação popular, mantendo-a dentro dos limites institucionais e tornando-se um instrumento de legitimação das políticas públicas, definidas e apresentadas com base nesta consulta popular. No entanto, os atores sociais demonstram inegável capacidade de "improvisarem", de reagirem e de apresentarem respostas e propostas que ultrapassem os limites dessa participação concedida. O próprio processo participativo pode possibilitar um aumento da consciência crítica, da capacidade de deliberar e de adquirir poder dos setores populares, fortalecendo os indivíduos e grupos, através da constante reflexão, avaliação e reorientação das práticas e decisões adotadas. 
Inegavelmente, os conselhos gestores das UCs são novos canais de participação, com potencial para ampliar e consolidar a consciência crítica, a democracia e a cidadania, na busca de construção de uma proposta de uma sociedade socioambientalmente mais justa, mesmo diante do risco de alguns se assumirem como detentores do "saber" da participação, usando sua posição de liderança e conhecimento nos grupos ou instituições para manipular os outros e perpetuar seus privilégios/interesses, burocratizando e desvirtuando o processo de participação.

$\mathrm{Na}$ verdade, os dois casos estudados revelaram formas específicas e contingentes de configuração da cidadania, em que todos lutam em defesa de seus interesses em nome de seus supostos "direitos". De uma maneira geral, o que se percebe é a inexistência de uma cidadania "pura", impermeável aos interesses pessoais, somente preocupada com um abstrato e genérico "bem comum". A visão de que o Sana estaria "contaminado" pelas práticas clientelísticas não pode encobrir o grande potencial e a novidade desta experiência histórica, que deve ser acompanhada com atenção. As particularidades das práticas políticas brasileiras não podem ser vistas como "desvios" de um modelo ideal de cidadania ativa, mas maneiras específicas dos cidadãos brasileiros alcançarem seus direitos no contexto de um Estado autoritário e de uma sociedade excludente. Os diferentes grupos criam formas próprias de atualização, de ressignificação dos direitos de cidadania conforme o contexto/grupo/interesse em nome do qual ela é acionada, de acordo com o processo histórico e as práticas de participação locais.

Mas ainda são necessários o aumento do grau de consciência política dos cidadãos, o reforço do controle popular sobre o poder político e econômico e o fortalecimento do grau de legitimidade do poder público, que deve promover o atendimento das necessidades reais da população. É preciso construir uma nova cultura política, uma nova qualidade de vida individual e coletiva, baseada nas idéias da obrigação política horizontal entre cidadãos, de participação e de solidariedade na formulação da vontade geral, com base na autonomia, no autogoverno, na descentralização, na democracia participativa, no cooperativismo e na produção socialmente útil. É preciso pensar em novas formas de cidadania, que sejam coletivas e não individuais e baseadas em outras formas de participação, em vez de direitos e deveres. 


\section{REFER ÊNCIAS BIBIOGRÁFICAS}

BARRETTO FILHO, H. T.. Da nação ao planeta através da natureza:uma abordagem antropológica das unidades de conservação de proteção integral na Amazônia brasileira. Tese de doutorado. São Paulo: USP/PPGAS/FFLCH, 2001.

BARTH, F.(org. Tomke Lask). O guru, o iniciador e outras variações antropológicas. Rio de Janeiro, Contracapa, 2000.

BORDENAVE, J.C. O que é participação. 8a ed. São Paulo: Brasiliense, 1994.

CARNEIRO, M.J. Ruralidades: novas identidades em construção. Estudos Sociedade e Agricultura. Rio de Janeiro: CPDA/UFRRJ; n.11, outubro de 1998.

CASTORIADIS, C. e CONH-BENDIT, D. Da ecologia à autonomia. São Paulo: Brasiliense, 1981.

CHAMBOREDON, J.C. La 'naturalisation' de la campagne: une autre maniére de cultiver les 'simples'.In:CADORET, A. Protection de la nature: histoire et idéologie. Paris, L'Harmmatan, 1985.

COZZOLINO, L.F. F. Unidades de conservação e desenvolvimento local: as APAs do Rio de Janeiro e seus processos de governança local. Dissertação de Mestrado. EICOS/UFRJ, 2005.

DAMATTA R. Conta de mentiroso: sete ensaios de antropologia brasileira. Rio de Janeiro: Rocco, 1994.

DEMO, P. Cidadania pequena: fragilidade e desafios do associativismo no Brasil. Campinas, SP: Autores Associados, 2001.

GASPAR, N.M.. Participação e exclusão na criação e gestão de uma área de proteção ambiental (apa) no norte fluminense. Rio de Janeiro: SBS, 2009.

GUTIÉRREZ, F. e PRADO, C. Ecopedagogia e cidadania planetária. São Paulo: Cortez, 2002.

OTTMANN, G. Cidadania mediada: processos de democratização da política municipal no Brasil.

INGOLD, T. The Perception of the Environment: Essays in Livelihood, Dwelling and Skill.

London: Routledge, 2000.

2007. . \& HALLAM, E. (orgs.) Creativity and cultural improvisation. N. York: Berg,

LEAL, V. N. . Coronelismo, enxada e voto, $5^{\mathrm{a}}$ ed. Rio de Janeiro: Alfa-Omega, 1975.

LOPES, J. S. L. Sobre processos de “ambientalização” dos conflitos e sobre dilemas da participação. Horizontes Antropológicos. Porto Alegre, ano 12, n.25, jan./jun., 2006.

MATHIEU,N. e JOLLIVET, M. (Orgs). Du rural à l'environnement: la question de la nature aujourd'hui. Paris, L'Harmmatan, 1989. 
MORIN, E. Complexidade e ética da solidariedade, in: Ensaios de complexidade. CASTRO, G. (org) et. al. Porto Alegre: Sulina, 1997.

. Os sete saberes essenciais à educação do futuro. Brasília/São Paulo: Unesco/Cortez, 2000.

MUSUMECI, L. Pequena produção e modernização da agricultura:o caso dos hortigranjeiros no estado do Rio de Janeiro. Rio de Janeiro, IPEA/INPES, 1987.

MAYER, J. M. e ARAÚJO, J. R. de. Teia serrana: formação histórica de Nova Friburgo. Rio de Janeiro: Ao Livro Técnico, 2003.

RAMBALDI, D. M. A Reserva da Biosfera da Mata Atlântica no Estado do Rio de Janeiro. - Rio de Janeiro: CNRBMA, n.22, fevereiro, 2003.

REGO, Virginia V.B. S. Mundos em confronto: o desenvolvimento do capitalismo e a ed ucação numa comunidade camponesa. Dissertação de Mestrado, PUC/RJ, 1988.

.Paraísos perdidos ou preservados? A conquista da cidadania em áreas de proteção ambiental. Brasília, IV Encontro da ANPPAS, 2008.

SAHLINS, M.O "pessimismo sentimental" e a experiência etnográfica: por que a cultura não é um "objeto" em via de extinção( parte I). Mana 3/2 (Estudos de Antropologia Social), Abril/97. Rio de Janeiro: PPGAS-UFRJ/Ed. Contracapa, 1997.

SANTILI, J. Socioambientalismo e novos direitos.Proteção jurídica à diversidade biológica e cultural. Brasília: IEB, 2004.

SANTOS, B. S. Pela mão de Alice: o social e o político na pós-modernidade. São Paulo: Cortez, 2003.

SOUSA JR, W. C. Gestão das águas no Brasil: Reflexões, diagnósticos e desafios. São Paulo: Peirópolis, 2004.

SPERANZA, J.S. Desenvolvimento local: aproximações entre o Banco Mundial e o debate brasileiro: limites ou possibilidades? Dissertação de Mestrado. CPDA/UFRRJ, 2005 .

TAVOLARO, S.B.E. Para além de uma "cidadania à brasileira":uma consideração critica da produção sociológica nacional. Rev. Sociologia e Política, Curitiba, v.17., n.32,p.95-120, fev.2009.

VIEIRA,L. Cidadania e Globalização. Rio de Janeiro/São Paulo: Record, 2002

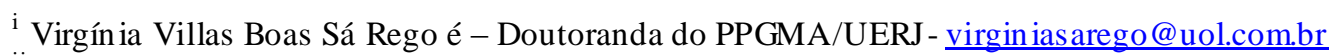

ii Orientadora: Rosane M. Prado e co-orientado: Marisa C.G. Rocha.

iii Criada pelo Decreto estadual no 29.213/2001, possui cerca de 35 mil hectares; abrange 40\% do município de Nova Friburgo (RJ), na zona de amortecimento no entorno do Parque Estadual de Três Picos (PETP), a maior unidade de conservação estadual de uso indireto, à qual se sobrepõe parcialmente.

${ }^{\text {iv }}$ Criada pela Lei municipal 2.172/2001, no $6^{\circ}$ dis trito do município de Macaé, co márea de 11.802 hectares.

v A definição do 'rural' enquanto categoria de análise científica é uma das questões recorrentes nas Ciências Sociais e é tarefa cada vez mais difícil, no contexto da sociedade globalizada, diante da multidimensionalidade e heterogeneidade existentes no espaço/meio considerado como rural e do esmaecimento de algu mas diferenças entre o rural e o u rbano. A definição adotada sobre o que é o rural tem consequências em relação ao campo científico, ao senso comum e,
} 
principalmente, ao campo das políticas públicas e das ações empresaria is dirigidas a esses espaços, visando "modernizálos", sob uma perspectiva tradicional ou pro mover o "desenvolvimento sustentável". Segundo o Instituto Brasile iro de Geografia e Estatística (IBGE), a área urbana corresponde à "área interna ao perímetro urbano de uma cidade ou vila, definida por lei municipal" e a área rural é a "área de um município externa ao perímetro urbano"(Cf.http://www.ibge.gov.br/home/geociencias/cartografia/manual_nocoes/elementos_representacao.html).

Assim, oficialmente, o espaço rural é definido como sendo o não urbano e os limites do urbano são definidos por legislação municipal, ou seja, por critérios políticos, geralmente dominados pelos interesses urbanos. Outro exemplo da definição oficial atual sobre o que é rural está presente no documento "Diretrizes para o Desenvolvimento do Turismo Rural" (Disponível em http://institucional.turis mo.gov.br/), produzido pelo Ministério do Turismo, que procura caracterizar o me io rural com base na territorialidade, na paisagem, pela biodiversidade e por um certo modo de vida relacionada à agricultura, à vida co munitária e à u ma relação mais íntima coma nature za.

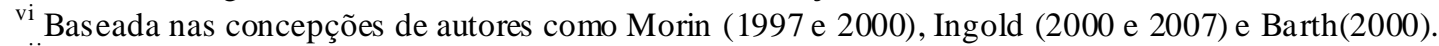

vii Refere-se a “(...)u m cidadão com capacidade de vigiar e participar na instrumentação das políticas públicas e com um projeto próprio para alcançar uma manipulação de recursos naturais mais racional e equitativo, e um entorno mais "habitável", compro metido co ma "planetariedade" (GUTIEERREZ E PRADO, 2002, p.16).

viii As concepções de "centro" e de "periferia" são bem problemáticas e devem ser relativizadas, pois onde é o "centro", onde é a "periferia" pode depender das perspectivas consideradas.

${ }^{\text {ix }}$ Para Santos, nas sociedades semiperiféricas, em relação aos "países centrais", como o Brasil e Portugal, a modernização do espaço da cidadania precedeu a do espaço de produção e teve certa autonomia em relação a ele. A lém disso, a separação entre as chamadas sociedade civil e sociedade política é bem menos nítida do que aquela geralmente identificada nos países centrais; o Estado tem papel central, sendo "ma is difícil determinar onde o Estado acaba e o não Estado começa"(SANTOS, 2003, p.130). No entanto, em decorrência da configuração interna do próprio poder do estado, o autoritaris mo estatal é ineficaz e contraditório. A burocracia do estado oscila entre a rigidez e o formalis mo, para o cidadão comum, e a extrema flexibilidade, informalidade e intimidade com que trata o cidadão com "boas referências".

${ }^{\mathrm{x}}$ Informações disponíveis no site http:www.pmm.gov.br.

${ }^{\text {xi }}$ Informações disponíveis no site: http:www.utenorteflu minense.com.br.

xii Informações disponíveis no site: http:www.ute mariolago.com.br.

xiii O Projeto Corredores Ecológicos do Ministério do Meio Ambiente (MMA) propõe uma abordagem alternativa às formas convencionais de conservação da biodiversidade, descentralizada e participativa, constituindo áreas onde se destacam ações coordenadas, para proteger a diversidade biológica na escala de biomas; englobam todas as áreas protegidas e os interstícios entre elas. Essas ações incentivam usos de baixo impacto, como o manejo florestal e os sistemas agroflorestais. O Projeto atua em dois corredores: O Corredor Central da Mata Atlântica (CCMA) e o Corredor Central da Amazônia (CCA); vem sendo construído desde 1997, no âmbito do Prog rama Piloto para a Proteção das Florestas Tropicais no Brasil, financiado pelo Fundo Fiduciário das Florestas Tropicais (RFT), administrado pelo Banco Mundial, pelos governos federal e estaduais, pelo Kreditanstalt für Wiederaufbau (KfW), órgão de cooperação internacional do governo ale mão, e pela Co missão Européia (http:www.mma.gov.br).

xiv O Programa de Reservas da Biosfera foi desenvolvido pela UNESCO para garantir a proteção e o reconhecimento internacional da importância de remanescentes significativos de ecossistemas. O reconhecimento da Reserva da Biosfera da Mata Atlântica, no Estado do Rio de Janeiro, iniciou-se em 1991 e, em 1993, ela ocupava $42 \%$ do território fluminense, com aproximadamente $18.476 \mathrm{~km}^{2}$, abrangendo mais da metade dos municípios fluminenses (RAMBALDI el al., 2003, p.16).

${ }^{x v}$ Dados do MMA (disponível em http:www.mma.gov.br).

${ }^{\text {xvi }}$ Sobre a história de Nova Friburgo, Cf. Mayer e Araújo (2003).

xvii Conforme analisado por Rego (1988).

xviii Cf Carneiro(1998).

${ }^{\text {xix }}$ Mathieu e Jolivet(1989) e Chamboredon (1985) identificam processos semelhantes na Europa.

${ }^{x x} \mathrm{O}$ processo de ambientalização surge em oposição ao processo de "devastação da natureza"; “(...)indicaria um processo histórico de construção de novos fenômenos, associado a um processo de interiorização pelas pessoas e pelos grupos sociais - e, no caso da "ambientalização", dar-se-ia uma interiorização das diferentes facetas da questão pública do "meio ambiente". Essa incorporação e essa naturalização de uma nova questão pública poderiam ser notadas pela transformação na forma e na linguagem de conflitos sociais e na sua institucionalização parcial'(LOPES, 2006, p.34). É um neologis mo, que adota o sufixo 'zação' para indicar sua dimensão processual, como outros usados nas Ciências Sociais (industrialização, u rbanização, etc).

xxi Bordenave (1994, p.29) define a participação concedida como "aquela provocada ou manipulada por agentes externos, para alcançar seus próprios objetivos, de acordo com a ideologia necessária para o exercício do projeto de direção-dominação da classe dominante".

xxii Ver análise de Speranza (2005) sobre o discurso instituído pelo Banco Mundial, a partir dos anos 1990.

xxiii Santili (2005), dentre outros identifica, no seio do movimento ambientalista, concepções preservacionistas e socioambientalistas, que se diferenciam quanto ao papel dos seres humanos na manutenção da biodiversidade e sua consequente "exclusão" ou "inclusão" em UCs. A implantação de UCs de proteção integral em áreas de florestas 
habitadas há milênios por grupos humanos, no Brasil e no mundo, tem gerado, dentre outros o problema dos "refugiados ambientais", que o socioambientalis mo - concepção própria do movimento ambiental brasileiro - visa evitar, propondo a inclusão das populações locais, vistas como "parceiras" nos projetos e ações de preservação ambiental.

xxiv Vieira $(2002$, p.228) diferencia a cidadania passiva, outorgada pelo Estado e fundada nos direitos individuais e privados, da cidadania ativa, baseada na participação no autogoverno e nos valores públicos, “(...) na qual o cidadão, portador de direitos e deveres é es sencialmente criador de direitos para abrir novos es paços de participação política".

xxv Segundo Sahlins (1997), nos anos 1950/60, em nome da modernização, acreditava-se que o capitalismo havia devastado as instituições, valores e consciência cultural dos diferentes povos, vistos como entraves ao desenvolvimento. No entanto, para ele, os povos indígenas vêm procurando elaborar ações e processos de resistência cultural diante da dominação colonial que sofreram, buscando "incorporar o sistema mundial a uma ordem ainda mais abrangente: seu próprio sistema de mundo", promovendo uma "indigenização" da modernidade. Assim, junto com o processo de integração das sociedades indígenas à economia global, ocorre u m aparentemente paradoxal enriquecimento da cultura tradicional: a indigenização e a globalização são processos complementares. A fragmentação étnica e cultural e a homogeneização modernista são duas tendências constitutivas da realidade global: "Assim dentro do ecúmeno global existem muitas novas formas de vida(...): formas sincréticas, translocais, multiculturais e neotradicionais" (Idem, p.58).

xxvi O conceito de "populações tradicionais" tem sido muito discutido pelo campo jurídico e pelas Ciências Sociais e Ambientais (dentre outros, por DIEGUES, 1996; CUNHA e ALMEIDA, 2002; BARRETO FILHO, 2005). O Artigo $3^{\circ}$ do decreto 6040/2007, que institui a Política Nacional de Desenvolvimento Sustentável dos Povos e Comunidades Tradicionais (PNPCT), define povos e comunidades tradicionais como "grupos culturalmente diferenciados e que se reconhecem como tais, que possuem formas próprias de organização social, que ocupam e us am territórios e recursos naturais como condição para sua reprodução cultural, social, religiosa, ancestral e econômica, utilizando conhecimentos, inovações e práticas geradas e transmitidas pela tradição".

${ }^{x x v i i}$ Em 2009, ocorreu a implantação do Instituto Estadual do Ambiente (INEA) (Lei 5101/2007), criado pelo govemo do estado, a partir da fusão da SERLA, FEEMA e do IEF.

xxviii Com base em dados do IBGE referentes ao associativis mo dos brasileiros, Demo (2001) constata o que denomina de "pequena" cidadania ativa da população brasileira, expressa por sua pequena participação em entidades e associações organizadas. Souza (2004) atribui a responsabilidade dessa situação à influência de uma forte corrente da tradição política e cultural baseada na cordialidade, no clientelismo, na troca de favores e no voto de cabresto, também constatada por Leal (1975), nos anos 1940. DaMatta (1993,p.93) defende a hipótese de que a construção da sociedade brasileira se realiza com base numa característica paradoxal do sistema social nacional, em que valores "modernos", como o individualis mo igualitário (subjacente à idéia de cidadania liberal) e as idéias de justiça social e progresso material coexistem, num círculo vicioso, com um conjunto de ideologias e práticas tradicionais, "que continuam se reproduzindo e governando relacional e hierarquica mente a sua vida social". Es te seria o "dilema brasileiro". 